\title{
The Beta-2-Adrenoreceptor Agonists, Formoterol and Indacaterol, but Not Salbutamol, Effectively Suppress the Reactivity of Human Neutrophils In Vitro
}

\author{
Ronald Anderson, ${ }^{1}$ Annette J. Theron, ${ }^{1,2}$ Helen C. Steel, ${ }^{1}$ Chrisna Durandt, ${ }^{1}$ \\ Gregory R. Tintinger, ${ }^{1}$ and Charles Feldman ${ }^{3}$ \\ ${ }^{1}$ Medical Research Council Unit for Inflammation and Immunity, Department of Immunology, Faculty of Health Sciences, \\ University of Pretoria, P.O. Box 2034, Pretoria 0001, South Africa \\ ${ }^{2}$ Tshwane Academic Division of the National Health Laboratory Service, Pretoria 0001, South Africa \\ ${ }^{3}$ Division of Pulmonology, Department of Internal Medicine, Faculty of Health Sciences, University of the Witwatersrand and Charlotte \\ Maxeke Johannesburg Academic Hospital, Johannesburg 2193, South Africa
}

Correspondence should be addressed to Ronald Anderson; ronald.anderson@up.ac.za

Received 8 November 2013; Revised 15 January 2014; Accepted 29 January 2014; Published 6 March 2014

Academic Editor: Giuseppe Valacchi

Copyright (C) 2014 Ronald Anderson et al. This is an open access article distributed under the Creative Commons Attribution License, which permits unrestricted use, distribution, and reproduction in any medium, provided the original work is properly cited.

\begin{abstract}
The clinical relevance of the anti-inflammatory properties of beta- 2 agonists remains contentious possibly due to differences in their molecular structures and agonist activities. The current study has compared the effects of 3 different categories of $\beta 2$-agonists, namely, salbutamol (short-acting), formoterol (long-acting) and indacaterol (ultra-long-acting), at concentrations of 1-1000 nM, with human blood neutrophils in vitro. Neutrophils were activated with either N-formyl-L-methionyl-L-leucyl-L-phenylalanine (fMLP, $1 \mu \mathrm{M}$ ) or platelet-activating factor (PAF, $200 \mathrm{nM}$ ) in the absence and presence of the $\beta 2$-agonists followed by measurement of the generation of reactive oxygen species and leukotriene B4, release of elastase, and expression of the $\beta 2$-integrin, CR3, using a combination of chemiluminescence, ELISA, colorimetric, and flow cytometric procedures respectively. These were correlated with alterations in the concentrations of intracellular cyclic-AMP and cytosolic $\mathrm{Ca}^{2+}$. At the concentrations tested, formoterol and indacaterol caused equivalent, significant $(P<0.05$ at $1-10 \mathrm{nM})$ dose-related inhibition of all of the pro-inflammatory activities tested, while salbutamol was much less effective $(P<0.05$ at $100 \mathrm{nM}$ and higher). Suppression of neutrophil reactivity was accompanied by elevations in intracellular cAMP and accelerated clearance of $\mathrm{Ca}^{2+}$ from the cytosol of activated neutrophils. These findings demonstrate that $\beta 2$-agonists vary with respect to their suppressive effects on activated neutrophils.
\end{abstract}

\section{Introduction}

Beta-2-adrenoreceptor ( $\beta 2 \mathrm{ARs})$ agonists ( $\beta 2$-agonists) are used primarily as bronchodilators in the therapy of obstructive airways disorders, especially bronchial asthma and chronic obstructive pulmonary disease (COPD) $[1,2]$. These agents also possess secondary anti-inflammatory properties, affecting cells of both the innate and adaptive immune systems and their inflammatory mediators in vitro, as well as in some animal models of experimental airway inflammation [3-5]. As with bronchodilatory activity, anti-inflammatory activity is achieved via sequential $\beta 2 \mathrm{AR}$-mediated activation of adenylyl cyclase, elevated intracellular concentrations of $3^{\prime}-5^{\prime}$-cyclic adenosine monophosphate (cAMP), and activation of cAMP-dependent protein kinase (PKA) [3-5]. While the therapeutic efficacy of the bronchodilatory actions of $\beta 2$-agonists is undisputed, the clinical relevance of the antiinflammatory activities of these agents remains uncertain $[3,5]$. This contention is underscored by data from recently reported large, well-controlled clinical trials demonstrating lack of efficacy of aerosolized or intravenous salbutamol in the therapy of acute lung injury $[6,7]$. Several mechanisms may underpin the apparent lack of anti-inflammatory potency of $\beta 2$-agonists in the clinical setting. These include (i) 
lower numbers of $\beta 2$-ARs on immune and inflammatory cells relative to airway smooth muscle cells, rendering them more susceptible to receptor desensitization [8], and (ii) possible variability in anti-inflammatory potency between different types of $\beta 2$-agonists resulting from differences in molecular structure.

In the current study, we have compared the antiinflammatory activities of two commonly used representatives of the short- and long-acting categories of $\beta 2$-agonists (SABA, LABA), namely, salbutamol and formoterol, respectively, with those of the recently introduced ultralong-acting (ultra LABA), indacaterol, used for maintenance therapy of airflow limitation in patients with COPD $[9,10]$. The study is focused on the effects of these agents on the proinflammatory activities of the human neutrophil, a cell type which not only expresses relatively high numbers of $\beta 2 \mathrm{ARs}$ in comparison with other types of immune and inflammatory cells $[5,11]$, but which is also intimately involved in the immunopathogenesis of COPD $[12,13]$. In addition, while several recent studies have addressed the anti-inflammatory interactions of indacaterol with human lung fibroblasts [14] and mast cells [15], the effects of this agent on human neutrophils have not been described.

\section{Materials and Methods}

2.1. Chemicals and Reagents. Formoterol fumarate dehydrate and salbutamol hydrochloride were purchased from SigmaAldrich (Pty) Ltd. (Johannesburg, South Africa), while indacaterol maleate was provided by Novartis International AG, Basel, Switzerland. All 3 agents were dissolved to a stock concentration of $10 \mathrm{mM}$ in dimethylsulfoxide (DMSO) and used at final concentrations of 1,10 , and $100 \mathrm{nM}$ in most of the assays described below and at $1-1000 \mathrm{nM}$ in others. The local concentration of formoterol following inhalation of $24 \mu \mathrm{g}$ of this agent has been estimated to be approximately $11 \mathrm{nM} \mathrm{[16].}$ The final concentration of DMSO in each assay was $0.1 \%$ and appropriate solvent controls were included with each experimental system. Unless indicated, all other chemicals and reagents were purchased from Sigma-Aldrich.

Neutrophils were activated with the chemoattractant, Nformyl-L-methionyl-L-leucyl-L-phenylalanine (fMLP, $1 \mu \mathrm{M}$ final) either alone or in combination with cytochalasin $\mathrm{B}(\mathrm{CB}$, $1 \mu \mathrm{M}$ final) in assays of oxygen consumption and degranulation. An additional chemoattractant, platelet-activating factor (PAF, $200 \mathrm{nM}$ final) was used in a more limited series of experiments.

2.2. Preparation of Neutrophils. The study was approved by the Faculty of Health Sciences Research Ethics Committee of the University of Pretoria, Pretoria, South Africa, and prior informed consent was obtained from all blood donors. Neutrophils were isolated from heparinized venous blood ( 5 units of preservative-free heparin per $\mathrm{mL}$ of blood) from nonsmoking healthy adult volunteers. Each subject completed a detailed health questionnaire and underwent a health check (including measurement of blood pressure) by an experienced, qualified nursing sister prior to venepuncture.
Neutrophils were separated from mononuclear leucocytes by centrifugation on Histopaque-1077 (Sigma Diagnostics, St. Louis, MO, USA) cushions at $400 \times \mathrm{g}$ for $25 \mathrm{~min}$ at room temperature. The resultant pellets were suspended in PBS $(0.15 \mathrm{M}, \mathrm{pH} 7.4)$ and sedimented with $3 \%$ gelatin to remove most of the erythrocytes. Following centrifugation $(280 \times \mathrm{g}$ at $10^{\circ} \mathrm{C}$ for $10 \mathrm{~min}$ ), residual erythrocytes were removed by selective lysis with $0.83 \%$ ammonium chloride at $4^{\circ} \mathrm{C}$ for $10 \mathrm{~min}$. The neutrophils, which were routinely of high purity (>90\%) and viability (>95\%), were resuspended to $1 \times 10^{7}$ cells $\mathrm{mL}^{-1}$ in PBS and held on ice until used.

2.3. Generation of Reactive Oxygen Species (ROS). This was measured using a luminol (5-amino-2,3-dihydro-1,4phthalazinedione)-enhanced chemiluminescence (LECL) procedure. Briefly, neutrophils $\left(10^{6}\right.$ cells) were preincubated for $10 \mathrm{~min}$ at $37^{\circ} \mathrm{C}$ in $900 \mu \mathrm{L}$ Hanks' balanced salt solution (HBSS, indicator-free; Highveld Biological (Pty) Ltd., Johannesburg, South Africa) containing luminol at a final concentration of $0.1 \mathrm{mM}$. Following preincubation, the test $\beta 2$-agonists $(1-1000 \mathrm{nM})$ or solvent control were added to the cells, followed after $20 \mathrm{~s}$ by fMLP $(1 \mu \mathrm{M})$, and LECL responses recorded using a Lumac Biocounter (model 2010; Lumac Systems Inc., Titusville, FL, USA). The final volume in each tube was $1 \mathrm{~mL}$, and the results, which are expressed in relative light units (rlu), are the peak values for fMLPactivated systems that were reached $40-50 \mathrm{~s}$ after addition of stimulant.

2.4. Oxygen Consumption. This was measured using a 3-channel oxygen electrode (Model DW1, Hansatech Ltd., King's Lynn, Norfolk, UK). Neutrophils $\left(2 \times 10^{6}\right)$ were incubated for $10 \mathrm{~min}$ at $37^{\circ} \mathrm{C}$ in HBSS after which the test $\beta 2$-agonists, at a fixed, final concentration of $100 \mathrm{nM}$, were added to the cells, followed $20 \mathrm{~s}$ later by $\mathrm{fMLP} / \mathrm{CB}$ $(1 \mu \mathrm{M}: 1 \mu \mathrm{M}) . \mathrm{PO}_{2}$ was monitored over an $8 \mathrm{~min}$ period and $\mathrm{O}_{2}$ consumption calculated over the period when utilization was linear (1-2 min), which was approximately $1 \mathrm{~min}$, and the results are expressed as nanomoles (nmols) $\mathrm{O}_{2}$ consumed $\min ^{-1}$ by $2 \times 10^{6}$ cells.

2.5. Elastase. Neutrophil degranulation was measured according to the extent of release of the primary granule enzyme, elastase. Neutrophils were incubated at a concentration of $2 \times 10^{6} \mathrm{~mL}^{-1}$ in HBSS for $10 \mathrm{~min}$ at $37^{\circ} \mathrm{C}$ followed by sequential addition of the test $\beta 2$-agonists $(1-1000 \mathrm{nM})$ and, $20 \mathrm{~s}$ later, by fMLP/CB $(1 \mu \mathrm{M}: 1 \mu \mathrm{M})$, and the tubes then incubated for $10 \mathrm{~min}$ at $37^{\circ} \mathrm{C}$. The tubes were then transferred to an ice bath, followed by centrifugation at $400 \times \mathrm{g}$ for $5 \mathrm{~min}$ to pellet the cells, and the supernatants were decanted and assayed for elastase using a micromodification of a standard colorimetric procedure. Briefly, $125 \mu \mathrm{L}$ of supernatant was added to the elastase substrate, $\mathrm{N}$-succinyl-L-analyl-L-analylL-alanine- $p$-nitroanilide $\left(3 \mathrm{mmol} \cdot \mathrm{L}^{-1}\right.$ in DMSO) in $0.05 \mathrm{M}$ Tris- $\mathrm{HCl}$ ( $\mathrm{pH} 8.0$ ), and elastase activity was monitored spectrophotometrically at a wavelength of $405 \mathrm{~nm}$. The results are expressed as milliunits enzyme per $2 \times 10^{6}$ cells. 
2.6. CR3 Expression. Expression of CR3 on resting and fMLP/CB $(1 \mu \mathrm{M}: 1 \mu \mathrm{M})$-activated neutrophils in the absence and presence of the test $\beta 2$-agonists (added as above) was measured flow cytometrically. Neutrophils $\left(1 \times 10^{6} \mathrm{~mL}^{-1}\right.$ final) were incubated in HBSS for $10 \mathrm{~min}$ at $37^{\circ} \mathrm{C}$ followed by addition of the $\beta 2$-agonists $(100 \mathrm{nM}$, fixed, final concentration) and activator. The tubes were incubated for $1 \mathrm{~min}$ and the reactions stopped by dilution of the cells in icecold medium. Phycoerythrin-labelled monoclonal antibody to CD11b (Beckman Coulter, Miami, FL, USA) was added in a $10 \mu \mathrm{L}$ volume to $1 \mathrm{~mL}$ of cell suspension and CR3 expression analyzed using a Gallios 10C Flow Cytometer (Beckman Coulter). The results were expressed as mean fluorescence intensity.

2.7. Measurement of Leukotriene B4 (LTB4) and cAMP. Competitive binding immunoassay procedures (CorrelateEIA; Assay Designs Inc., Ann Arbor, MI, USA) were used to measure LTB4 in the supernatants of fMLP $(1 \mu \mathrm{M})$ or PAF $(200 \mathrm{nM})$-activated neutrophils, while cAMP was assayed in the extracts of unstimulated cells in the absence and presence of the test $\beta 2$-agonists. In the case of LTB4, neutrophils $\left(2 \times 10^{6} \mathrm{~mL}^{-1}\right)$ were preincubated for $10 \mathrm{~min}$ at $37^{\circ} \mathrm{C}$ after which the test $\beta 2$-agonists (10 and $100 \mathrm{nM}$, final) were added followed $20 \mathrm{~s}$ later by fMLP or PAF. Incubation was terminated $5 \mathrm{~min}$ later by the addition of an equal volume of ice-cold HBSS to the tubes, which were then held in an ice bath prior to pelleting the cells by centrifugation. The cell-free supernatants were then diluted $(1: 8)$ and assayed for LTB4, with the results expressed as pg LTB4 per $10^{7}$ cells.

In the case of cAMP, neutrophils $\left(2 \times 10^{6} \mathrm{~mL}^{-1}\right)$ were preincubated for $10 \mathrm{~min}$ at $37^{\circ} \mathrm{C}$ after which the test $\beta 2$ agonists (10 and $100 \mathrm{nM}$ ) were added and the reactions terminated $20 \mathrm{~s}$ later by the addition of an equal volume of ice-cold HBSS to the tubes. Following centrifugation, the supernatants were discarded and cAMP extracted from the cell pellets by addition of $0.1 \mathrm{M} \mathrm{HCl}$ for $30 \mathrm{~min}$ followed by centrifugation to remove cell debris and the supernatants decanted and assayed for cAMP. These results are expressed as pmol cAMP per $10^{7}$ cells.

2.8. Spectrofluorimetric Measurement of Cytosolic $\mathrm{Ca}^{2+}$. Fura2 acetoxymethyl ester (fura-2AM) was used as the fluorescent, $\mathrm{Ca}^{2+}$-sensitive indicator for these experiments [17]. Neutrophils $\left(1 \times 10^{7} \mathrm{~mL}^{-1}\right)$ were incubated with fura-2AM $(2 \mu \mathrm{M})$ for $30 \mathrm{~min}$ at $37^{\circ} \mathrm{C}$ in PBS, washed and resuspended in HBSS. The fura-2-loaded cells $\left(2 \times 10^{6} \mathrm{~mL}^{-1}\right)$ were then preincubated for $10 \mathrm{~min}$ at $37^{\circ} \mathrm{C}$ after which they were transferred to disposable reaction cuvettes which were maintained at $37^{\circ} \mathrm{C}$ in a Hitachi $65010 \mathrm{~S}$ fluorescence spectrophotometer with excitation and emission wavelengths set at 340 and $500 \mathrm{~nm}$, respectively. After a stable baseline was obtained $( \pm 1 \mathrm{~min})$, test agents $(1-100 \mathrm{nM})$ or solvent control were added to the relevant systems followed $20 \mathrm{~s}$ later by fMLP $(1 \mu \mathrm{M})$ or PAF $(200 \mathrm{nM})$ and alterations in fluorescence intensity were monitored over a 5-10 min time course. Alterations in cytosolic $\mathrm{Ca}^{2+}$ concentrations following activation of neutrophils with fMLP or PAF were calculated using procedures described in detail elsewhere, either as absolute concentrations [17] or by calculating the areas under the curve using the fura-2/AM tracings [16]. In the case of the latter, the tracings were manually copied, electronically scanned, and saved in jpg format. These images were then imported into the area calculator software program, SketchandCalc, and results are expressed as $\mathrm{cm}^{2}$.

A modification of this procedure, namely, $\mathrm{Mn}^{2+}$ quenching of fura-2 fluorescence, was used to monitor the effects of the test $\beta 2$-agonists (10 and $100 \mathrm{nM}$ ) on store-operated uptake of extracellular $\mathrm{Ca}^{2+}$ by activated neutrophils. Briefly, cells $\left(2 \times 10^{6} \mathrm{~mL}^{-1}\right)$ loaded with fura-2/AM as described above were preincubated for $8 \mathrm{~min}$ at $37^{\circ} \mathrm{C}$ followed by successive addition of $\mathrm{Mn}^{2+}(600 \mu \mathrm{M})$ for a further 2 min period, then the test $\beta 2$-agonists followed $20 \mathrm{~s}$ later by fMLP $(1 \mu \mathrm{M})$ or PAF $(200 \mathrm{nM}) . \mathrm{Ca}^{2+}$ influx was then determined according to the rate and magnitude of quenching of fura-2-fluorescence, using an excitation wavelength of $360 \mathrm{~nm}$, which is an isosbestic wavelength, and an excitation wavelength of $500 \mathrm{~nm}$. These results are presented as the traces from 2 separate experiments, as well as by measurement of the rate of decline in fluorescence intensity at 1 and $4 \mathrm{~min}$ following addition of the chemoattractants.

2.9. Cell Viability. Neutrophils $\left(1 \times 10^{6} / \mathrm{mL}\right)$ were treated with formoterol, indacaterol, or salbutamol, at a final concentration of $100 \mathrm{nM}$ for $10-15 \mathrm{~min}$ at $37^{\circ} \mathrm{C}$, followed by a $10 \mathrm{~min}$ exposure of the cells to propidium iodide (DNA prepstain, Beckman Coulter Miami, FL, USA, $50 \mu \mathrm{g} / \mathrm{mL}$ ), at room temperature with flow cytometric detection of uptake of propidium iodide as a marker of cell membrane damage expressed as \% viable cells.

2.10. Statistical Analysis. With the exception of the results of the oxygen consumption and fura-2/AM fluorescence experiments, some of which are presented as representative traces, the results of each series of experiments are presented as the mean \pm SEM values, where $n$ equals the number of different donors used in each series of experiments, with the number of replicates for each drug concentration and drug-free control system shown in the figure legends. Levels of statistical significance were determined by comparing the absolute values for each drug-treated system with the corresponding values for the relevant drug-free control systems for each assay using the Mann-Whitney test.

\section{Results}

3.1. Production of Reactive Oxygen Species. These results are shown in Figure 1. Treatment of neutrophils with either formoterol or indacaterol at concentrations of $1-1000 \mathrm{nM}$ caused dose-related inhibition of the generation of ROS which achieved statistical significance at concentrations of $\geq 10 \mathrm{nM}$ $(P<0.0188-0.004)$, thereafter gradually leveling off, possibly due to $\beta 2 A R$ saturation, with the 2 agents being essentially equipotent. Salbutamol was less effective, only attaining statistically significant inhibition at $1000 \mathrm{nM}(P<0.04)$. 


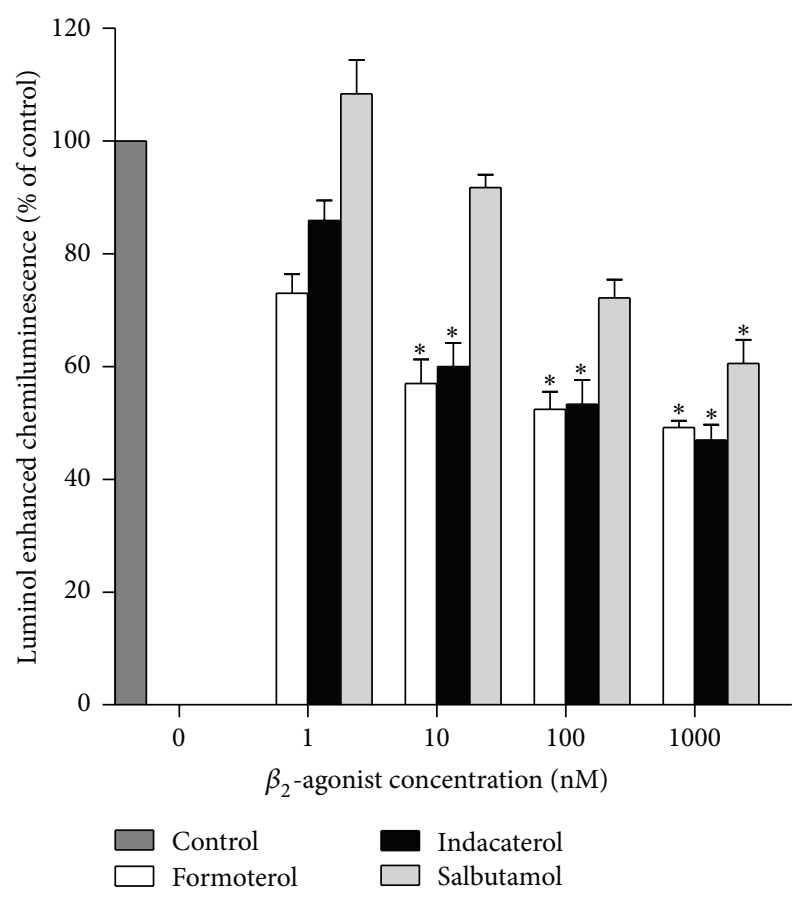

FIGURE 1: Effects of formoterol, indacaterol, and salbutamol (1$1000 \mathrm{nM}$ ) on the luminol-enhanced chemiluminescence responses of neutrophils activated by N-formyl-L-methionyl-L-leucyl-Lphenylalanine (fMLP, $1 \mu \mathrm{M}$ ). The results are expressed as the mean percentage of control \pm SEM $(n=5)$ with duplicate values for each drug concentration and control system in each experiment. The absolute values for unstimulated neutrophils and for cells activated with fMLP in the absence of the drugs were $2136 \pm 219$ and $20394 \pm 1447$ relative light units respectively; ${ }^{*} P<0.04-0.004$ for comparison with the fMLP-activated, drug-free control system.

3.2. Oxygen Consumption. As shown in Figure 2, which depicts the traces from 3 separate experiments using cells from 3 different donors, activation of neutrophils with fMLP/CB was accompanied by a marked, transient increase in $\mathrm{O}_{2}$ consumption by the cells which was linear for about 1$2 \mathrm{~min}$, declining rapidly thereafter. Inclusion of the test $\beta 2$ agonists at a fixed final concentration of $100 \mathrm{nM}$ decreased the utilization of $\mathrm{O}_{2}$ by these cells. The mean values \pm SEMs for the complete series of experiments $(n=3)$ for the fMLP/CB-activated control system and for systems containing formoterol, indacaterol, and salbutamol were $65.4 \pm 3$, $44.7 \pm 3(P<0.0022$ by comparison with the control system $)$, $40.0 \pm 4(P<0.0022)$, and $50.3 \pm 2(P<0.0022) \mathrm{nmol} \mathrm{O}_{2}$ consumed by $2 \times 10^{6}$ cells $\mathrm{min}^{-1}$, respectively, over the $1 \mathrm{~min}$ period when the response was linear.

3.3. Release of Elastase. These results are shown in Figure 3. Treatment of neutrophils with either formoterol or indacaterol at concentrations of $\geq 1 \mathrm{nM}$ caused significant $(P<$ 0.0001 ) dose-related inhibition of the release of elastase, again leveling off at around $10 \mathrm{nM}$. Salbutamol was less effective, attaining statistically significant inhibition at concentrations of $\geq 10 \mathrm{nM}(P<0.0001)$.

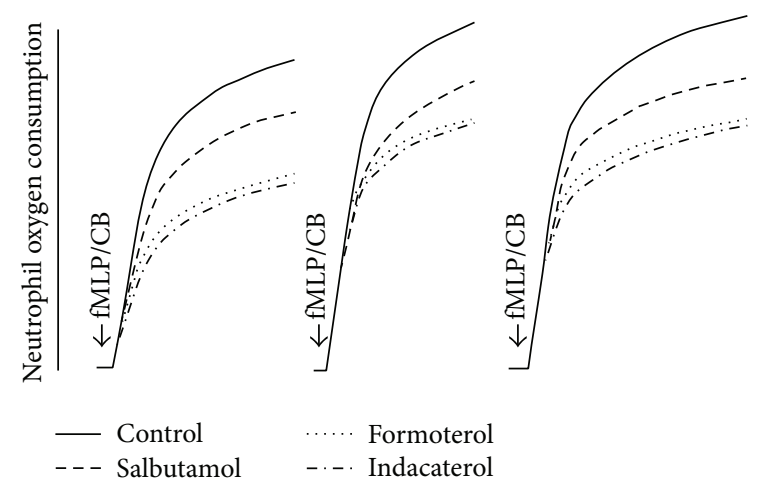

Figure 2: Typical traces from 3 separate experiments $(n=$ 3) showing the effects of formoterol, indacaterol, and salbutamol at $100 \mathrm{nM}$ on the magnitude of oxygen consumption by neutrophils activated with $\mathrm{N}$-formyl-L-methionyl-L-leucyl-Lphenylalanine $(1 \mu \mathrm{M}) /$ cytochalasin B $(1 \mu \mathrm{M})(\mathrm{fMLP} / \mathrm{CB})$.

3.4. CR3 Expression. Both formoterol and indacaterol, but not salbutamol, at the fixed concentration used (100 nM) caused statistically significant inhibition of expression of CR3 by fMLP/CB-activated neutrophils. The values for the unstimulated control system and for fMLP/CB-activated systems in the absence and presence of formoterol, indacaterol, or salbutamol were $58 \pm 4,121 \pm 6,97 \pm 5(P<0.0045$ by comparison with the control system), $99 \pm 5(P<0.0071)$, and $110 \pm 6$ (NS) mean fluorescence intensity, respectively, $(n=7)$.

3.5. Leukotriene B4. The effects of the test $\beta 2$-agonists on the production of LTB4 by neutrophils activated with fMLP or PAF are shown in Figure 4. At the concentrations tested (10 and $100 \mathrm{nM}$ ), both formoterol and indacaterol caused doserelated, essentially equivalent, statistically significant $(P<$ 0.001) inhibition of LTB4 production activated by either chemoattractant, while the effects of salbutamol were evident at $100 \mathrm{nM}$ only $(P<0.001)$.

3.6. Cyclic AMP. These results are shown in Figure 5. Treatment of neutrophils with formoterol and indacaterol for $20 \mathrm{~s}$ at both concentrations used (10 and $100 \mathrm{nM})$ resulted in significant $(P<0.0001)$ and comparable elevations in intracellular cAMP, while salbutamol was apparently ineffective at these concentrations. No clear dose-response relationship was evident with formoterol and indacaterol consistent with $\beta 2 \mathrm{AR}$ saturation at $10 \mathrm{nM}$ of these agents.

3.7. Cytosolic $\mathrm{Ca}^{2+}$. The results shown in Figure 6 are traces from 2 representative experiments showing the effects of formoterol, indacaterol, and salbutamol (10 and $100 \mathrm{nM}$ ) on the alterations in cytosolic $\mathrm{Ca}^{2+}$ following activation of the cells with either fMLP or PAF, while data from the full series of experiments are summarized in Table 1. In the case of fMLP, addition of the chemoattractant to neutrophils resulted in the abrupt, characteristic increase in cytosolic $\mathrm{Ca}^{2+}$ (fura2 fluorescence) originating predominantly via mobilization of the cation from intracellular stores, rising from a basal 


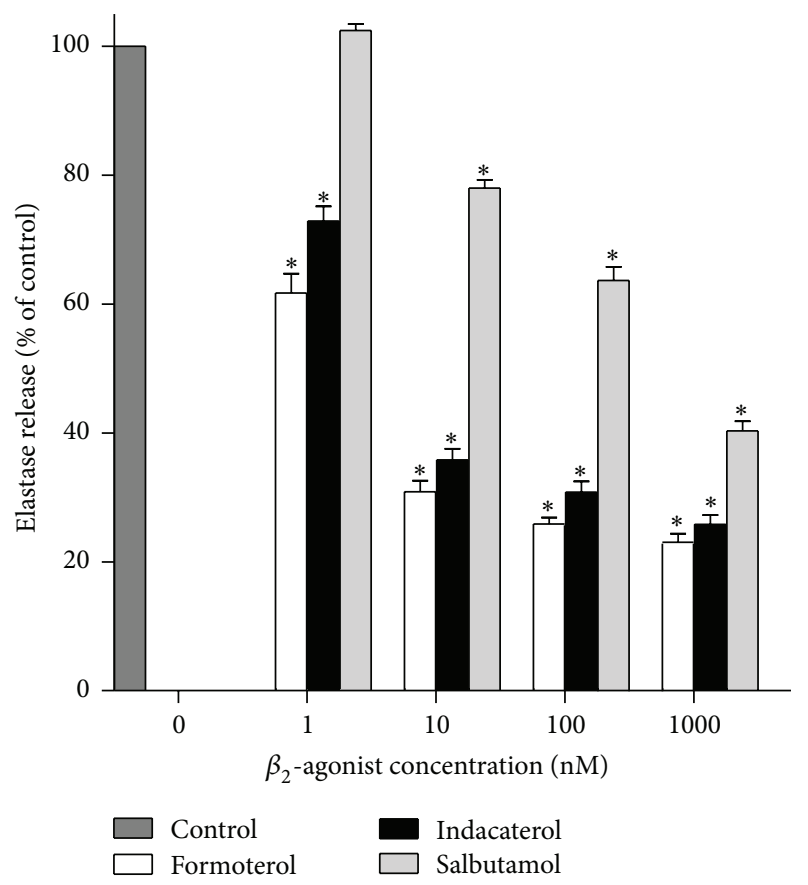

Figure 3: Effects of formoterol, indacaterol, and salbutamol (1$1000 \mathrm{nM}$ ) on the release of elastase from neutrophils activated with $\mathrm{N}$-formyl-L-methionyl-L-leucyl-L-phenylalanine $(1 \mu \mathrm{M}) /$ cytochalasin $\mathrm{B}(1 \mu \mathrm{M})(\mathrm{fMLP} / \mathrm{CB})$. The results of 3 separate experiments $(n=3)$ with 5 replicates for each drug concentration and control system in each experiment are expressed as the mean percentage of control \pm SEM. The absolute values for the unstimulated control system and for cells activated with $\mathrm{fMLP} / \mathrm{CB}$ were $47 \pm 6$ and $1551 \pm 78$ milliunits elastase per $10^{7}$ cells. ${ }^{*} P<0.0102-0.0001$ for comparison with the drug-free control systems.

concentration of $89 \pm 7 \mathrm{nM}$ to $364 \pm 31 \mathrm{nM} \mathrm{Ca}^{2+}$. This was followed by a rapid decline over an approximately $2 \mathrm{~min}$ period due to clearance of cytosolic $\mathrm{Ca}^{2+}$ and a slowing thereafter due to store-operated influx of the cation, respectively [18]. Treatment of the cells with the $\beta 2$-agonists did not affect the magnitude of the initial peak increase in cytosolic $\mathrm{Ca}^{2+}$ (not shown). However, as shown in Figure 6 and Table 1 , all 3 agents accelerated the rate of decline in fluorescence intensity attaining statistical significance with formoterol and indacaterol at concentrations of $10 \mathrm{nM}$, but not in the case of salbutamol. These findings are compatible with $\beta 2$-agonistmediated enhancement of the clearance of $\mathrm{Ca}^{2+}$ from the cytosol of fMLP-activated neutrophils.

Activation of neutrophils with PAF also resulted in an abrupt increase in the concentration of cytosolic $\mathrm{Ca}^{2+}$ which persisted for about $1 \mathrm{~min}$ due to rapid influx of the cation, which, relative to fMLP, was followed by a more gradual clearance of the cation as reported previously [19]. The effects of the $3 \beta 2$-agonists on PAF-activated alterations in neutrophil cytosolic $\mathrm{Ca}^{2+}$ were comparable to those of fMLP-activated cells, namely, no effects on immediate peak responses, followed by accelerated clearance of the cation, with formoterol and indacaterol being most effective (Figure 6, Table 1).
TABLE 1: Effects of formoterol, indacaterol, and salbutamol $(1,10$, 100 , and $1000 \mathrm{nM}$ ) on the cytosolic $\mathrm{Ca}^{2+}$ concentrations (area under curve) of FMLP- and PAF-activated neutrophils.

\begin{tabular}{lcc}
\hline Agent & $\begin{array}{c}\text { FMLP } \\
\text { Mean } \pm \text { SEM }\left(\mathrm{cm}^{2}\right)\end{array}$ & $\begin{array}{c}\text { PAF } \\
\text { Mean } \pm \text { SEM }\left(\mathrm{cm}^{2}\right)\end{array}$ \\
\hline Control (DMSO) & $8.6 \pm 0.64$ & $13.8 \pm 0.53$ \\
Formoterol 1 nM & $\mathrm{ND}$ & $10.9 \pm 0.90$ \\
Indacaterol 1 nM & $\mathrm{ND}$ & $12.2 \pm 1.34$ \\
Salbutamol 1 nM & $\mathrm{ND}$ & $14.3 \pm 1.20$ \\
Formoterol 10 nM & $4.8 \pm 0.64^{*}$ & $10.9 \pm 0.74^{*}$ \\
Indacaterol 10 nM & $5.6 \pm 0.56^{*}$ & $10.9 \pm 1.08^{*}$ \\
Salbutamol 10 nM & $7.3 \pm 0.50$ & $13.6 \pm 1.25$ \\
Formoterol 100 nM & $4.5 \pm 0.28^{*}$ & $9.8 \pm 0.90^{*}$ \\
Indacaterol 100 nM & $5.1 \pm 0.57^{*}$ & $10.7 \pm 0.90^{*}$ \\
Salbutamol 100 nM & $7.7 \pm 0.74$ & $12.8 \pm 1.40$ \\
Formoterol 1000 nM & $\mathrm{ND}$ & $8.0 \pm 0.74^{*}$ \\
Indacaterol 1000 nM & $\mathrm{ND}$ & $8.4 \pm 0.90^{*}$ \\
Salbutamol 1000 nM & $\mathrm{ND}$ & $10.3 \pm 1.90$ \\
\hline
\end{tabular}

ND: not done.

${ }^{*} P=0.02-0.0003$.

The effects of the $3 \beta 2$-agonists on store-operated influx of extracellular $\mathrm{Ca}^{2+}$ following activation of neutrophils with either fMLP or PAF are shown in Figure 7 which are the traces from 2 representative experiments; these are summarized in Table 2. At the concentrations tested (10 and $100 \mathrm{nM})$, formoterol and indacaterol effectively inhibited the influx of $\mathrm{Ca}^{2+}$ by cells activated with either fMLP or PAF, while the effects of salbutamol were evident at a concentration of $1000 \mathrm{nM}$.

3.8. Cell Viability. Exposure of the neutrophils to formoterol, indacaterol, or salbutamol at a final concentration of $100 \mathrm{nM}$ had no effect on cell viability according to propidium iodide exclusion, the respective values being $95.9 \pm 0.5 \%, 95.9 \pm 0.5 \%$ and $96.0 \pm 0.5 \%$ viability relative to a control value of $96.4 \pm$ $0.6 \%$ (data from eight determinations).

\section{Discussion}

The findings of the current study demonstrate that formoterol and indacaterol effectively suppress a spectrum of proinflammatory activities of activated human neutrophils in vitro, while salbutamol is much less effective. The different magnitudes of anti-inflammatory activity observed with formoterol, indacaterol, and salbutamol are most likely due to variability in the intrinsic efficacy of these agents. Formoterol, a full agonist [5] and indacaterol, a near full agonist [20], have higher intrinsic efficacy than the partial agonist, salbutamol [5]. With respect to formoterol and indacaterol, all of the neutrophil functions tested were suppressed at low nanomolar $(1-10 \mathrm{nM})$ concentrations of these agents including the generation of ROS and LTB4, release of the primary granule protease, elastase, and expression of the $\beta 2$-integrin, CR3. These neutrophil-derived mediators of inflammation are 


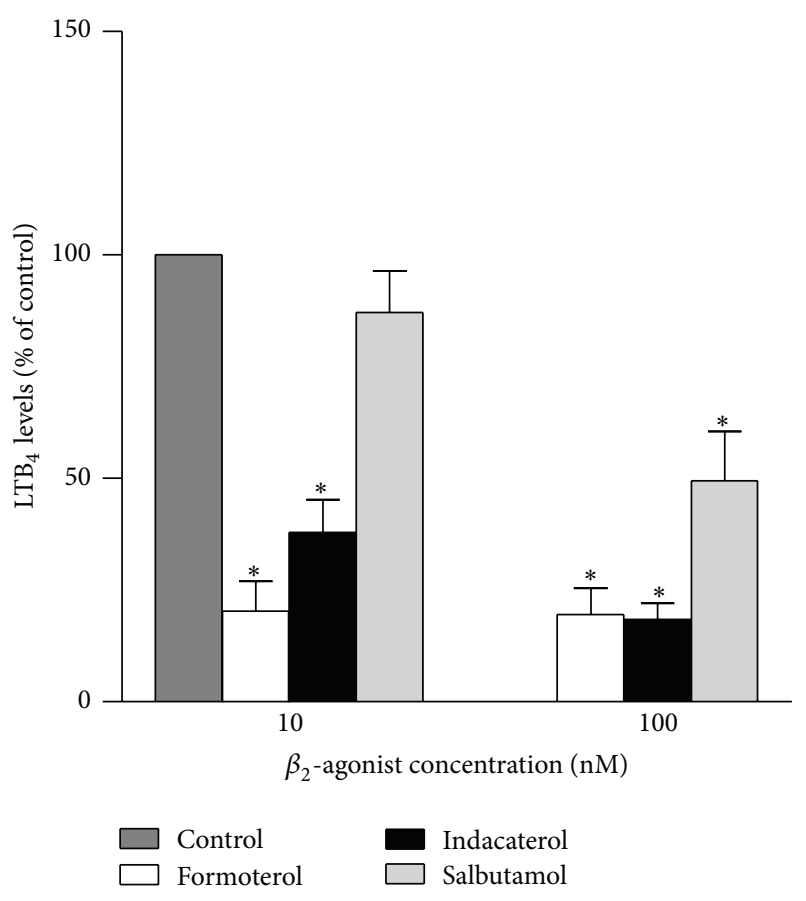

(a)

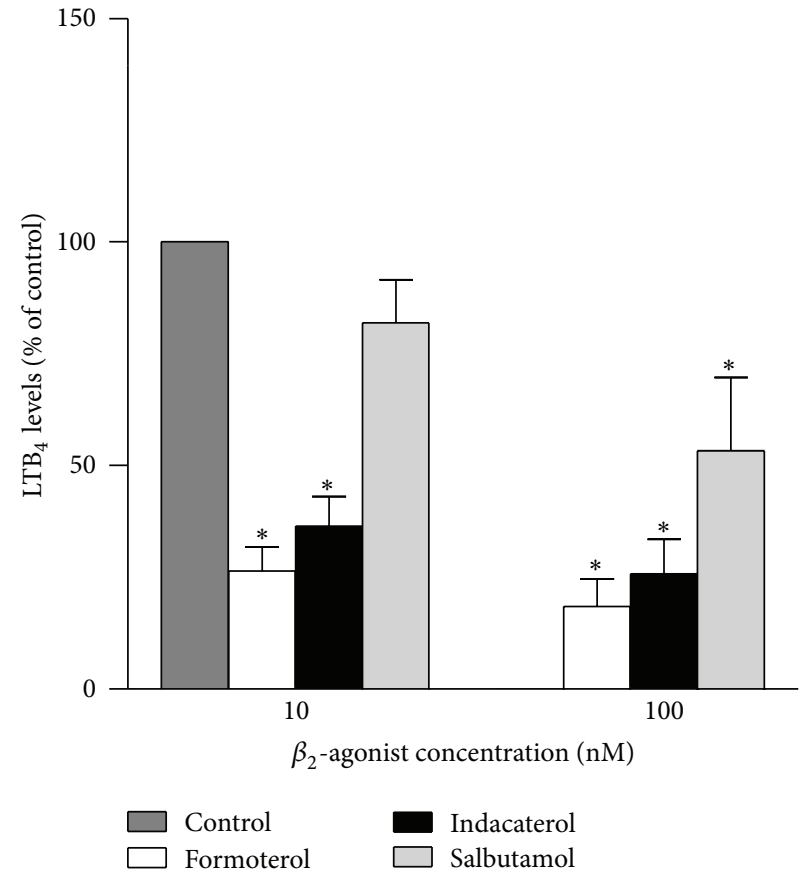

(b)

FIGURE 4: Effects of formoterol, indacaterol, and salbutamol (10 and $100 \mathrm{nM})$ on the production of LTB $_{4}$ by fMLP- (a) and PAF- (b) activated neutrophils. The results of 5 separate experiments $(n=5)$ with 2 replicates for each drug concentration and control system in each experiment are expressed as the mean percentage of control \pm SEM. The absolute values for the unstimulated control system and for cells activated with either fMLP or PAF were $33 \pm 7,1095.4 \pm 362.2$, and $1546 \pm 1108.5 \mathrm{pg} \mathrm{mL}^{-1} .{ }^{*} \mathrm{P}<0.001$ for comparison with the drug-free control systems.

TABLE 2: Effects of formoterol, indacaterol, and salbutamol on $\mathrm{Mn}^{2+}$ quenching of fura-2 fluorescence in FMLP- and PAF-activated neutrophils.

\begin{tabular}{lcccc}
\hline Agent & \multicolumn{2}{c}{ FMLP-activated neutrophils } & \multicolumn{2}{c}{ PAF-activated neutrophils } \\
& $\begin{array}{c}\text { Magnitude of decrement } \\
\text { at 1 minute }(\mathrm{cm}) \\
\text { Mean } \pm \text { SEM }\end{array}$ & $\begin{array}{c}\text { Magnitude of decrement } \\
\text { at 4 minutes }(\mathrm{cm}) \\
\text { Mean } \pm \text { SEM }\end{array}$ & $\begin{array}{c}\text { Magnitude of decrement } \\
\text { at 1 minute }(\mathrm{cm}) \\
\text { Mean } \pm \text { SEM }\end{array}$ & $\begin{array}{c}\text { Magnitude of decrement } \\
\text { at 4 minutes }(\mathrm{cm}) \\
\text { Mean } \pm \text { SEM }\end{array}$ \\
\hline Control (DMSO) & $1.40 \pm 0.09$ & $5.40 \pm 0.30$ & $2.7 \pm 0.15$ & $7.4 \pm 0.67$ \\
Formoterol 100 nM & $1.24 \pm 0.09$ & $3.70 \pm 0.13^{*}$ & $2.5 \pm 0.16$ & $5.1 \pm 0.55^{*}$ \\
Indacaterol 100 nM & $1.30 \pm 0.07$ & $3.74 \pm 0.19^{*}$ & $2.4 \pm 0.17$ & $5.2 \pm 0.50$ \\
Salbutamol 100 nM & $1.60 \pm 0.09$ & $5.30 \pm 0.22$ & $2.7 \pm 0.17$ & $6.8 \pm 0.73$ \\
\hline
\end{tabular}

${ }^{*} P=0.04-0.009$.

intimately involved in the immunopathogenesis not only of COPD, but also other acute and chronic inflammatory diseases of the airways such as severe persistent bronchial asthma, COPD, cystic fibrosis, bronchiolitis obliterans, and acute respiratory distress syndrome, resulting in pulmonary abnormalities including bronchial hyperresponsiveness and obstruction, mucus hypersecretion, and airway remodeling [10, 21-27].

From a mechanistic perspective, exposure of neutrophils to formoterol and indacaterol, at concentrations equivalent to those which suppressed neutrophil reactivity, resulted

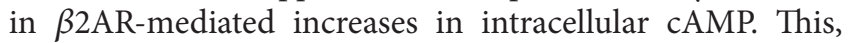
in turn, apparently underpins the increased efficacy of restoration of $\mathrm{Ca}^{2+}$ homeostasis to neutrophils activated with either fMLP or PAF, with consequent attenuation of $\mathrm{Ca}^{2+}$-dependent proinflammatory activity. Several mechanisms have been described, all involving cAMP-dependent protein kinase (PKA), whereby cAMP promotes accelerated clearance of $\mathrm{Ca}^{2+}$ from the cytosol of activated neutrophils and other cell types (reviewed in 5). However, PKAmediated enhancement of the efficacy of the $\mathrm{Ca}^{2+}$ resequestering endomembrane $\mathrm{Ca}^{2+}$-ATPase, which diverts mobilized cytosolic $\mathrm{Ca}^{2+}$ back into storage compartments [28], is likely to be the predominant mechanism operative in the setting of the observed $\beta 2$-agonist/neutrophil interactions. This contention is based on the following observations: (i) the lack of effect of the test agents on the immediate peak cytosolic $\mathrm{Ca}^{2+}$ response following exposure of the cells to fMLP or PAF, 


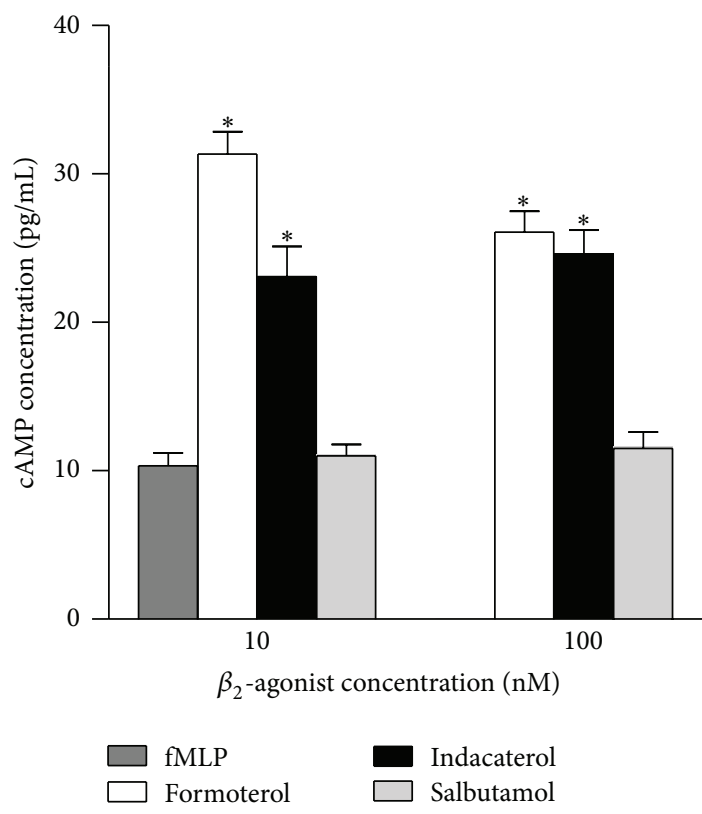

FIGURE 5: Effects of formoterol, indacaterol, and salbutamol (10 and $100 \mathrm{nM}$ ) on cAMP levels in neutrophils. The results of 5 separate experiments $(n=5)$ with 2 replicates for each drug concentration and control system in each experiment are expressed as the mean \pm SEM. The absolute value for the control system was $10.4 \pm 0.9 \mathrm{pg}$ $\mathrm{mL}^{-1} .{ }^{*} P<0.001$ for comparison with the drug-free control systems.

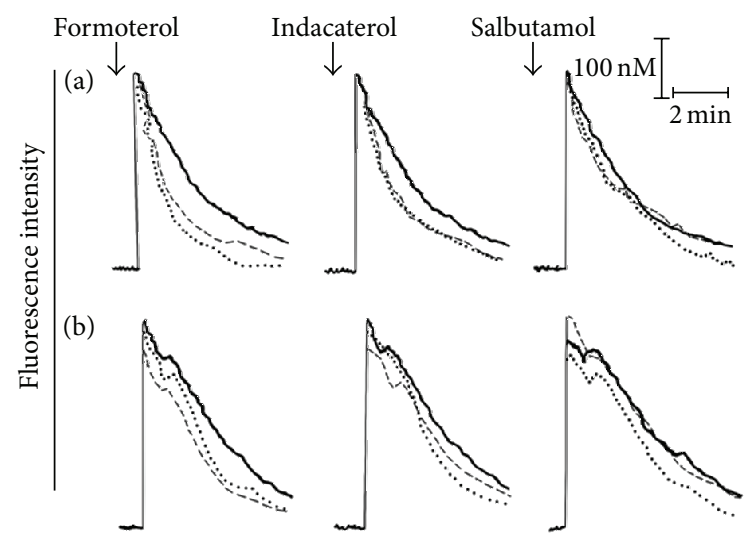

FIGURE 6: Fura-2 fluorescence traces from 2 representative experiments ( $n=4-7$ in the series) showing the effects of formoterol, indacaterol, and salbutamol $(10$ and $100 \mathrm{nM})$ on the alterations in cytosolic $\mathrm{Ca}^{2+}$ concentrations following activation of the cells with either $1 \mu \mathrm{M}$ fMLP (a) or $200 \mathrm{nM}$ PAF (b). The 3 lines in each trace correspond to the control system (-) and systems treated with

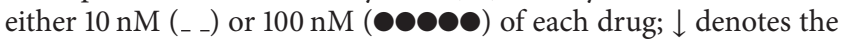
addition of either fMLP or PAF.

excluding interference with phospholipase $\mathrm{C}$ and generation of $\mathrm{Ca}^{2+}$-mobilizing inositol triphosphate, and (ii) decreased store-operated influx of extracellular $\mathrm{Ca}^{2+}$ which is probably secondary to efficient utilization of cytosolic $\mathrm{Ca}^{2+}$ for store refilling [28].

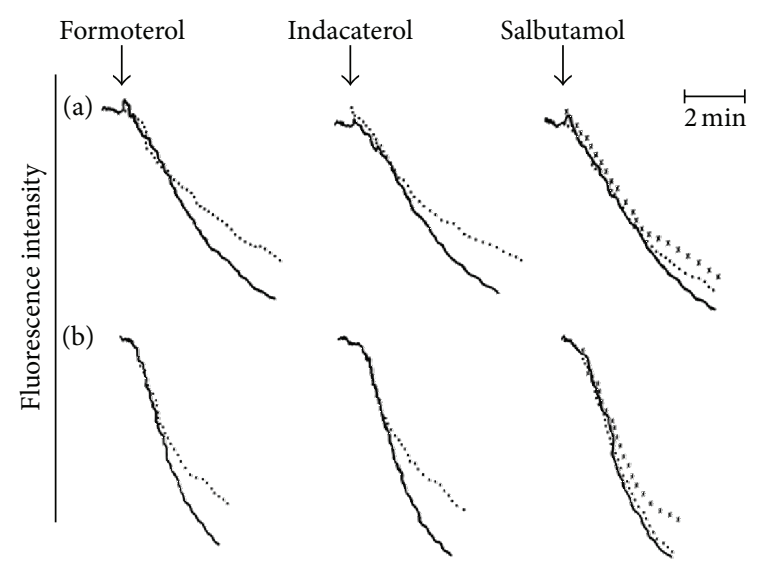

FIgURE 7: $\mathrm{Mn}^{2+}$-quenching of fura-2 fluorescence traces from 2 representative experiments ( $n=3$ in the series) showing the effects of formoterol, indacaterol $(100 \mathrm{nM})$, and salbutamol (100 and $1000 \mathrm{nM}$ ) on the alterations in cytosolic $\mathrm{Ca}^{2+}$ concentrations following activation of the cells with either $1 \mu \mathrm{M}$ fMLP (a) or $200 \mathrm{nM}$ PAF (b). The 3 lines in each trace correspond to the control system (-)

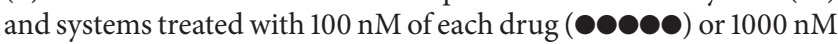
salbutamol (xxxx); $\downarrow$ denotes the addition of either fMLP or PAF.

The apparent disconnect between the failure to detect elevated levels of intracellular cAMP in the setting of moderate inhibition of oxygen consumption, generation of ROS and LTB4, and release of elastase following treatment of neutrophils with salbutamol at a concentration of $100 \mathrm{nM}$ may be attributed to several reasons. Firstly, as a consequence of both the partial agonist activity and comparatively low partition coefficient of salbutamol, sustained elevations in cAMP may be difficult to detect due to rapid hydrolysis of the cyclic nucleotide by the cyclic AMP-specific phosphodiesterase, PDE4. This contention is substantiated by the findings of a previous study demonstrating that the elevating actions of salbutamol on neutrophil cAMP are dependent on the inclusion of an inhibitor, either selective or nonselective, of PDEs [16]. Alternatively, salbutamol may suppress the proinflammatory activities of neutrophils by mechanisms unrelated to $\beta 2$ AR-mediated activation of adenylyl cyclase [29]. Importantly, the anti-inflammatory effects of formoterol and indacaterol could not be attributed to cellular cytotoxicity.

Despite a considerable body of evidence demonstrating potent, cAMP-dependent, suppressive effects of $\beta 2$-agonists on cells of the innate and adaptive immune systems in vitro $[3,5,28]$, as well as anti-inflammatory activity in animal models of experimental airways inflammation [30], compelling evidence for the existence of these activities in the clinical setting has not been forthcoming $[6,7]$. This may be attributable to several possible causes. These are (i) aspects of molecular structure, as mentioned above, such as those in the case of formoterol and indacaterol which confer full agonist activity, good partition coefficients, and long duration of action, as opposed to salbutamol [5]; (ii) failure to attain adequate concentrations in the airways, although inhalation of $24 \mu \mathrm{g}$ formoterol has been estimated to result in a local concentration of $11 \mathrm{nM}$ [16], which would be effective for this agent, but ineffective in the case of salbutamol; 
and (iii) lower numbers of $\beta 2$ ARs on inflammatory cells relative to airway smooth muscle cells $[8,11]$, possibly resulting in an increased propensity to undergo receptor desensitization [8]. Of these, $\beta 2 \mathrm{AR}$ desensitization is likely to be the major obstacle to harnessing the anti-inflammatory potential of formoterol and indacaterol in the clinical setting. In addition to augmenting $\beta 2 \mathrm{AR}$ expression by combining $\beta$-agonists with inhaled corticosteroids [31, 32], potential strategies to overcome receptor desensitization in the clinical setting include adjunctive therapy using selective and nonselective inhibitors of cyclic AMP PDEs and possibly anticholinergics such as the long-acting antimuscarinic, tiotropium [5].

Numerous clinical trials have confirmed the clinical efficacy of indacaterol for the treatment of patients with moderate and severe COPD [33]. In this clinical setting indacaterol provides extended relief of airflow obstruction and dyspnoea and reduces the frequency of exacerbations, resulting in symptomatic relief and a decreased requirement for rescue medications, thereby improving patient quality of life and adherence to therapy $[10,33,34]$. Indacaterol also appears to have a favourable safety profile. In the case of the cardiovascular system for example, 14 days of therapy did not induce any prolongation of the QT interval [35]. This is important as many patients with COPD are elderly and may have associated comorbid cardiovascular disorders. A mild and transient cough is a common adverse effect described by patients treated with indacaterol [34].

In conclusion, indacaterol, like formoterol, effectively targets the potentially harmful activities of stimulated neutrophils in vitro. These anti-inflammatory, albeit secondary, actions of both agents may contribute to their therapeutic efficacy in COPD.

\section{Conflict of Interests}

Charles Feldman has acted on the Advisory Boards and/or received honoraria for lectures and/or received assistance for congress travel from Aspen-GSK, Boehringer Ingelheim, Cipla Medpro, and Novartis. The other authors have no conflict of interests to declare.

\section{Acknowledgments}

This study was supported by research grants awarded to Ronald Anderson and Charles Feldman by the Medical Research Council and National Research Foundation of South Africa, respectively.

\section{References}

[1] M. Cazzola, C. P. Page, P. Rogliani, and M. G. Matera, “ $\beta$-agonist therapy in lung disease," American Journal of Respiratory and Critical Care Medicine, vol. 187, no. 7, pp. 690-696, 2013.

[2] M. R. Sears, "The FDA-mandated trial of safety of long-acting beta-agonists in asthma: finality or futility?” Thorax, vol. 68, no. 2, pp. 195-198, 2013.

[3] M. Johnson, "Effects of $\beta 2$-agonists on resident and infiltrating inflammatory cells," Journal of Allergy and Clinical Immunology, vol. 110, no. 6, pp. S282-S290, 2002.
[4] C. H. Serezani, M. N. Ballinger, D. M. Aronoff, and M. PetersGolden, "Cyclic AMP: master regulator of innate immune cell function," American Journal of Respiratory Cell and Molecular Biology, vol. 39, no. 2, pp. 127-132, 2008.

[5] A. J. Theron, H. C. Steel, G. R. Tintinger, C. Feldman, and R. Anderson, "Can the anti-inflammatory activities of $\beta 2$-agonists be harnessed in the clinical setting?" Journal of Drug Design, Development and Therapy, vol. 2013, no. 7, Article ID S50995, pp. 1387-11398, 2013.

[6] M. A. Matthay, R. G. Brower, S. Carson et al., "Randomized, placebo-controlled clinical trial of an aerosolized $\beta 2$-agonist for treatment of acute lung injury," American Journal of Respiratory and Critical Care Medicine, vol. 184, no. 5, pp. 561-568, 2011.

[7] F. G. Smith, G. D. Perkins, S. Gates et al., "Effect of intravenous $\beta-2$ agonist treatment on clinical outcomes in acute respiratory distress syndrome (BALTI-2): a multicentre, randomised controlled trial," The Lancet, vol. 379, no. 9812, pp. 229-235, 2012.

[8] P. J. Barnes, "Effect of $\beta$-agonists on inflammatory cells," Journal of Allergy and Clinical Immunology, vol. 104, no. 2, part 2, pp. S10-S17, 1999.

[9] S. M. Ray, J. C. McMillen, S. A. Treadway, R. S. Helmer, and A. S. Franks, "Indacaterol: a novel long-acting $\beta(2)$-agonist," Pharmacotherapy, vol. 32, no. 5, pp. 456-474, 2012.

[10] J. Han, L. Dai, and N. Zhong, "Indacaterol on dyspnea in chronic obstructive pulmonary disease: a systematic review and meta-analysis of randomized placebo-controlled trials," $B M C$ Pulmonary Medicine, vol. 13, article 26, 2013.

[11] C. De Coupade, R. W. Gear, P. F. Dazin, H. Y. Sroussi, P. G. Green, and J. D. Levine, " $\beta 2$-adrenergic receptor regulation of human neutrophil function is sexually dimorphic," British Journal of Pharmacology, vol. 143, no. 8, pp. 1033-1041, 2004.

[12] K. Hoenderkos and A. Condliffe, "The neutrophil in chronic obstructive pulmonary disease," American Journal of Respiratory Cell and Molecular Biology, vol. 48, no. 5, pp. 531-539, 2013.

[13] P. J. Barnes, "New molecular targets for the treatment of neutrophilic diseases," Journal of Allergy and Clinical Immunology, vol. 119, no. 5, pp. 1055-1062, 2007.

[14] S. L. Tannheimer, C. D. Wright, and M. Salmon, "Combination of roflumilast with a beta-2 adrenergic receptor agonist inhibits proinflammatory and profibrotic mediator release from human lung fibroblasts," Respiratory Research, vol. 13, article 28, 2012.

[15] A.-M. Scola, M. Loxham, S. J. Charlton, and P. T. Peachell, “The long-acting $\beta$-adrenoceptor agonist, indacaterol, inhibits IgEdependent responses of human lung mast cells," British Journal of Pharmacology, vol. 158, no. 1, pp. 267-276, 2009.

[16] C. M. Gravett, A. J. Theron, H. C. Steel et al., "Interactive inhibitory effects of formoterol and montelukast on activated human neutrophils," The European Respiratory Journal, vol. 36, no. 6, pp. 1417-1424, 2010.

[17] G. Grynkiewicz, M. Poenie, and R. Y. Tsien, "A new generation of $\mathrm{Ca}^{2+}$ indicators with greatly improved fluorescence properties," The Journal of Biological Chemistry, vol. 260, no. 6, pp. 3440-3450, 1985.

[18] R. Anderson and A. G. Mahomed, "Calcium efflux and influx in f-met-leu-phe (fMLP)-activated human neutrophils are chronologically distinct events," Clinical and Experimental Immunology, vol. 110, no. 1, pp. 132-138, 1997.

[19] H. C. Steel and R. Anderson, "Dissociation of the PAF-receptor from NADPH oxidase and adenylate cyclase in human neutrophils results in accelerated influx and delayed clearance of cytosolic calcium," British Journal of Pharmacology, vol. 136, no. 1, pp. 81-89, 2002. 
[20] M. Cazzola and M. G. Matera, "Emerging inhaled bronchodilators: an update," European Respiratory Journal, vol. 34, no. 3, pp. 757-769, 2009.

[21] J. C. W. Mak and M. M. W. Chan-Yeung, "Reactive oxidant species in asthma," Current Opinion in Pulmonary Medicine, vol. 12, no. 1, pp. 7-11, 2006.

[22] K.-Y. Lee, S.-C. Ho, H.-C. Lin et al., "Neutrophil-derived elastase induces TGF- $\beta 1$ secretion in human airway smooth muscle via NF- $\kappa$ B pathway," American Journal of Respiratory Cell and Molecular Biology, vol. 35, no. 4, pp. 407-414, 2006.

[23] Q. Li, X. Zhou, H. Yu, X. Nie, and X. Xu, "Roles of ROS/TACE in neutrophil elastase-induced mucus hypersecretion in NCIH292 airway epithelial cells," European Cytokine Network, vol. 21, no. 3, pp. 177-185, 2010.

[24] H. Ohnishi, N. Miyahara, and E. W. Gelfand, "The role of leukotriene B4 in allergic diseases," Allergology International, vol. 57, no. 4, pp. 291-298, 2008.

[25] I. T. Lee and C. M. Yang, "Role of NADH oxidase/ROS in pro-inflammatory mediators-induced airway and pulmonary diseases," Biochemical Pharmacology, vol. 84, no. 5, pp. 581-590, 2012.

[26] A. Gaggar, A. Hector, P. E. Bratcher, M. A. Mall, M. Griese, and D. Hartl, "Series "matrix metalloproteinases in lung health and disease": the role of matrix metalloproteinases in cystic fibrosis lung disease," The European Respiratory Journal, vol. 38, no. 3, pp. 721-727, 2011.

[27] R. A. Sandhaus and G. Torino, "Neutrophil elastase-mediated lung disease," COPD, vol. 10, supplement 1, pp. 60-63, 2013.

[28] R. Anderson, A. Goolam Mahomed, A. J. Theron, G. Ramafi, and C. Feldman, "Effect of rolipram and dibutyryl cyclic AMP on resequestration of cytosolic calcium in FMLP-activated human neutrophils," British Journal of Pharmacology, vol. 124, no. 3, pp. 547-555, 1998.

[29] I. Brunskole Hummel, M. T. Reinartz, S. Kälble et al., "Dissociations in the effects of $\beta 2$-adrenergic receptor agonists on cAMP formation and superoxide production in human neutrophils: support for the concept of functional selectivity," PLOS ONE, vol. 8, no. 5, Article ID e64556, 2013.

[30] M. Bosmann, J. J. Grailer, K. Zhu et al., "Anti-inflammatory effects of $\beta 2$ adrenergic receptor agonists in experimental acute lung injury," The FASEB Journal, vol. 26, no. 5, pp. 2137-2144, 2012.

[31] J. L. Black, B. G. G. Oliver, and M. Roth, "Molecular mechanisms of combination therapy with inhaled corticosteroids and longacting $\beta$-agonists," Chest, vol. 136, no. 4, pp. 1095-1100, 2009.

[32] K. F. Chung, G. Caramori, and I. M. Adcock, "Inhaled corticosteroids as combination therapy with $\beta$-adrenergic agonists in airways disease: present and future," European Journal of Clinical Pharmacology, vol. 65, no. 9, pp. 853-871, 2009.

[33] E. Ridolo, M. Montagni, E. Olivieri, G. G. Riario-Sforza, and C. Incorvaia, "Role of indacaterol and the newer very longacting $\beta 2$-agonists in patients with stable COPD: a review," International Journal of Chronic Obstructive Pulmonary Disease, vol. 2013, no. 8, pp. 425-432, 2013.

[34] A. Rossi and G. Polese, "Indacaterol: a comprehensive review," International Journal of Chronic Obstructive Pulmonary Disease, vol. 2013, no. 8, pp. 353-363, 2013.

[35] S. Khindri, R. Sabo, S. Harris, R. Woessner, S. Jennings, and A. F. Drollmann, "Cardiac safety of indacaterol in healthy subjects: a randomized, multidose, placebo- and positive-controlled, parallel-group thorough QT study," BMC Pulmonary Medicine, vol. 11, article 31, 2011. 


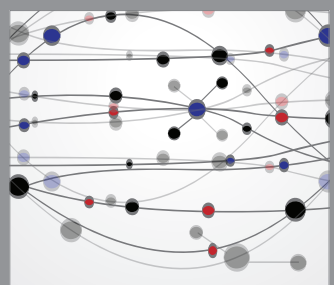

The Scientific World Journal
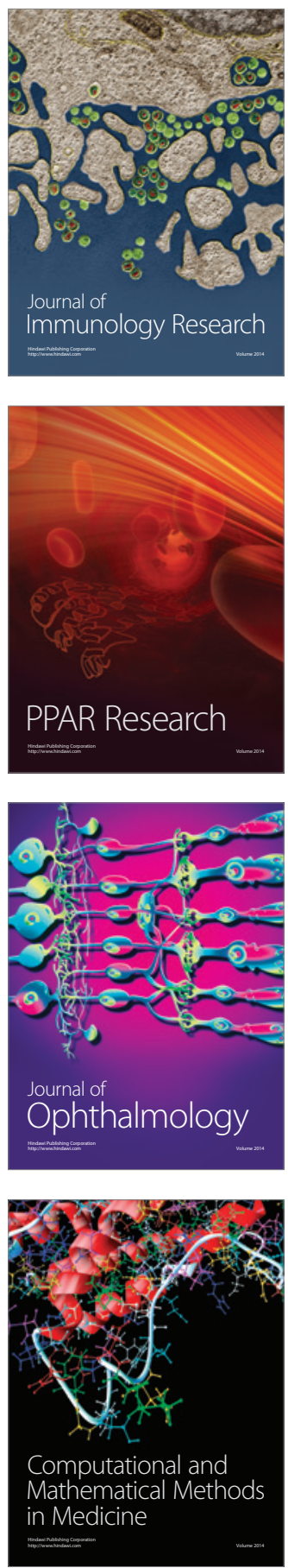

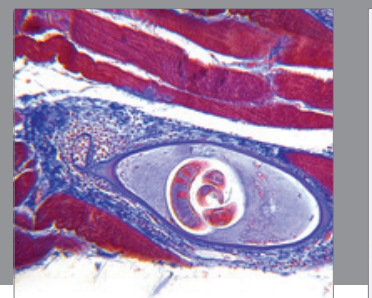

Gastroenterology

Research and Practice
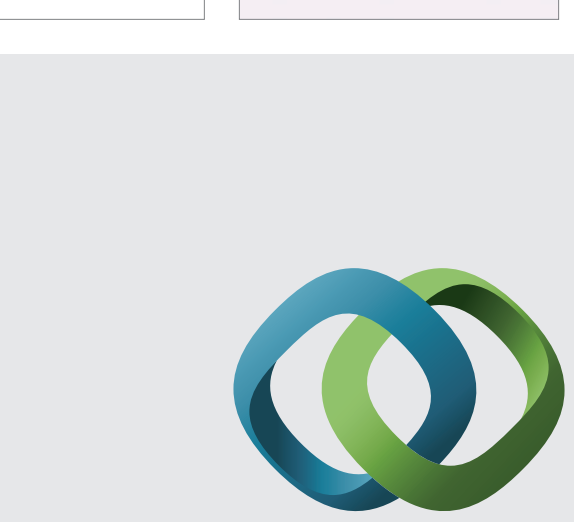

\section{Hindawi}

Submit your manuscripts at

http://www.hindawi.com
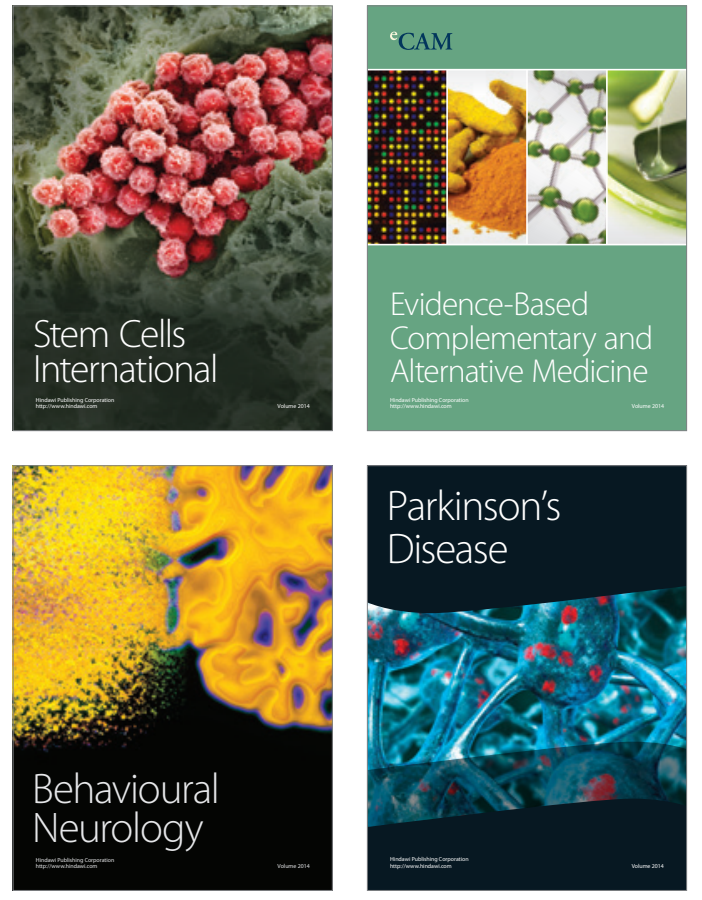
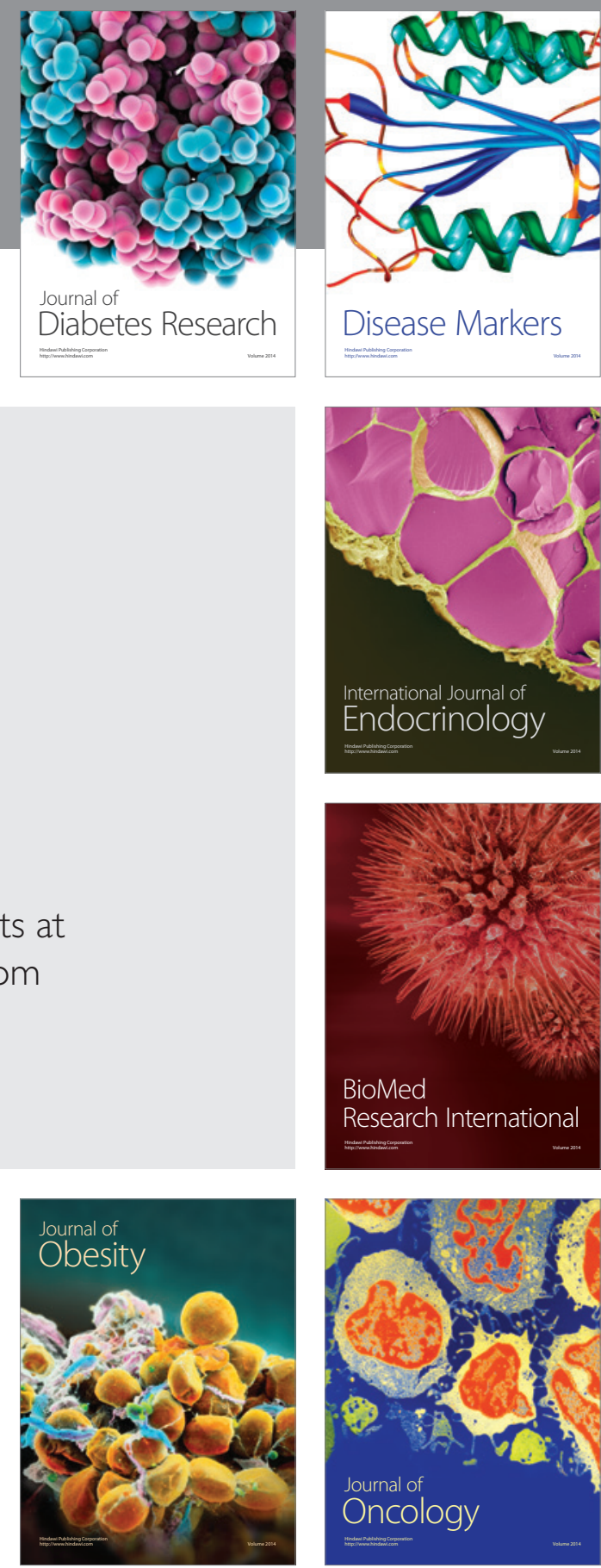

Disease Markers
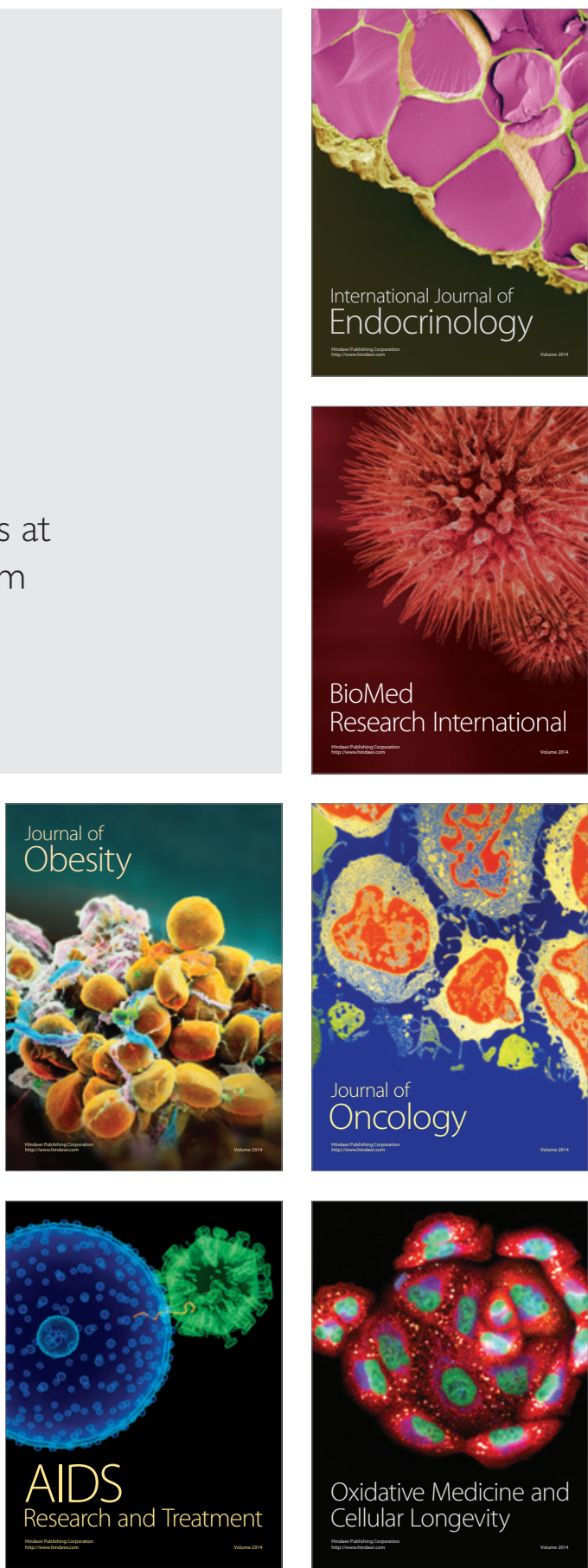